\title{
Multiplex Detection of Hotspot Mutations by Rolling Circle-Enabled Universal Microarrays
}

\author{
Daniela P. Ladner, John H. Leamon, Stefan Hamann, Gemma Tarafa, \\ Todd Strugnell, Deborah Dillon, Paul Lizardi, and José Costa \\ Department of Pathology (DPL, JHL, SH, TS, DD, PL, JC), Yale New Haven Hospital, Yale University, \\ New Haven, Connecticut; and Institut Catala d' Oncologia (GT), L'Hospitalet, Barcelona, Spain
}

SUMMARY: Detection of somatic low abundance mutations in early cancer development requires a discriminatory, specific, and high-throughput methodology. In this study we report specific, discriminatory detection of low abundance mutations through a novel combination of rolling circle amplification (Nat Genet 1998; 19:225-232) and PCR ligation detection reaction on a universal oligonucleotide microarray (J Mol Biol 1999; 292:251-262). After mutation-specific multiplex ligation and hybridization of 17 pairs of probes to a generic microarray, the ligated probes were visualized. The multiplex mutation-specific ligation is possible only because rolling circle amplification permits quantification of previously undetectable hybridization events conducive to the detection of a single mutation from within a pool of over 100 wild-type alleles. This system is readily adaptable to high-throughput automation using a robot such as the Biomek platform. (Lab Invest 2001, 81:1079-1086).

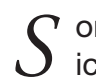
omatic mutations are found in tissues and biological fluids. In principle, detailed analysis of these mutations could serve as a biomarker for cancer risk, but mutated alleles are infrequent and diverse even within a locus. High-throughput genetic analysis for mutations has so far been effective only when the proportion of mutated alleles is above $5 \%$, or when analyzing single nucleotide polymorphisms or germ line mutations. Although high discrimination is achieved by size fractionation methodologies such as single stranded conformation polymorphism (Orita et al, 1989) and denaturing gradient gel electrophoresis, these methods cannot be multiplexed and are therefore not easily adapted to high-throughput automation. Solid-phase mutational screening technologies, such as multiplex allele-specific diagnostic assays (Shuber et al, 1997), sequencing by hybridization (Broude et al, 1994; Hacia et al, 1996), trapped oligonucleotide incorporation (Prezant and FishelGhodsian, 1992), and allele primer extension assays (Pastinen et al, 2000), offer parallel analysis of large numbers of mutations with potential savings in cost and time. To date, however, specificity for these strategies is often low (Hatch et al, 1999), and, at best, discrimination is limited to detection of $5 \%$ mutated alleles (Pastinen et al, 2000). The ligase detection reaction (LDR) has been successfully used to detect single-base mutations in different loci with high specificity (Day et al, 1995; Eggerding et al, 1995). LDR

Received February 13, 2001

This work was supported by Early Detection Research Network Grant No. CA 85065-03.

Address reprint requests to: Prof. José Costa, Department of Pathology, Yale New Haven Hospital, East Pavillion 2-607, 20 York Street, New Haven, CT-06520. E-mail: jose.costa@yale.edu permits discrimination of 1:100 or even 1:500 mixtures of mutant alleles in an excess of wild-type alleles (Gerry et al, 1999). This system permitted detection of point mutations in tumor and cell line DNA. Recently, simultaneous analysis of multiple mutations was achieved by combining LDR with a generic microarray (Gerry et al, 1999; Witowski et al, 2000), allowing simultaneous analysis of multiple mutations.

The potential for high discrimination and automation of this system prompted us to adapt it for detection of somatic mutations present at very low abundance. We found that when the number of multiplexed probes exceeded five, detection of mutated alleles was unreliable and often gave false positive results. We have surmounted this problem through the introduction of rolling circle amplification (RCA), which is an effective method of signal amplification for mutation detection on solid substrates, including glass slides (Lizardi et al, 1998; Thomas et al, 1999) and beads (Hatch et al, 1999). Combining LDR with RCA on a universal microarray enabled the detection, with high sensitivity, of 17 mutational hotspots from multiplex ligation reactions.

\section{Results}

Genomic DNA was initially amplified by PCR. Point mutations were detected with sets of ligatable probes composed of upstream and downstream oligonucleotides. Successful ligations with a Cy-5 fluorophore attached to the downstream probe were hybridized to mutation-specific "zipcodes" located on generic oligonucleotide microarrays (Gerry et al, 1999). As shown by Gerry et al in solitary discrimination tests involving a single set of probes, microarray-based PCR/LDR detected mutations present in $1 \%$ of the sample DNA without RCA signal enhancement at a 
signal-to-background ratio of 2:1. However, multiplex reactions involving simultaneous use of 5 to 17 pairs of probes were not successful. The signal intensity was too weak to reliably detect mutant alleles on the generic oligonucleotide microarray.

To allow simultaneous use of multiple probes and enhance the discriminatory power of the assay, we incorporated a rolling circle primer into the downstream oligonucleotide probe. RCA was used to generate a multimeric DNA strand from the ligated probes hybridized to the array. The RCA product was then labeled by hybridization of fluorescently labeled oligonucleotides. The principle of this method is depicted in Figure 1.

Genomic DNA for 17 hotspot mutations was initially amplified by PCR for KRAS exon 1 and p53 exon 7 .
The LDR assay was performed in a solution containing amplified PCR sample and upstream and downstream probes for mutation detection. Upstream probes were designed to carry the point mutation of interest on the $3^{\prime}$ ends of a 20 base-pair strand, attached to a 24 base-pair zipcode address on their 5 ' ends. Every upstream probe specific for a mutation carries a different zipcode address designated for this mutation. Every downstream probe, complementary to template PCR, carries a rolling circle primer on its $3^{\prime}$ end. Only in the presence of mutated template DNA will the corresponding upstream probe be ligated to the downstream probe and combine the designated zipcode address with the RCA primer. LDR product is then hybridized onto the generic zipcode microarray, allowing each zipcode address to find its complemen-

A: a)
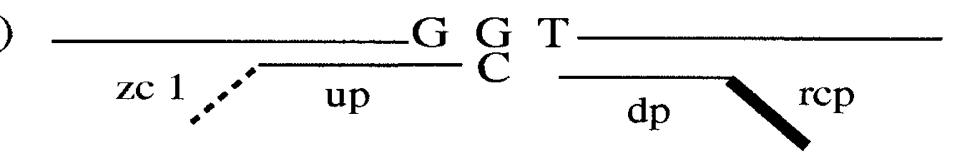

b)

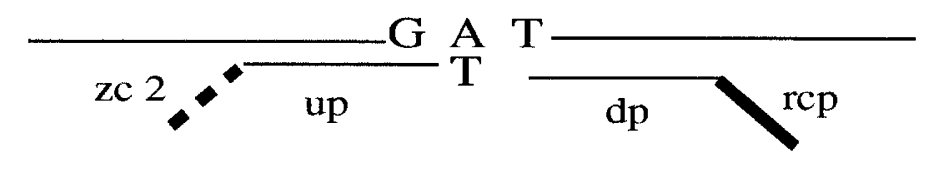

B:

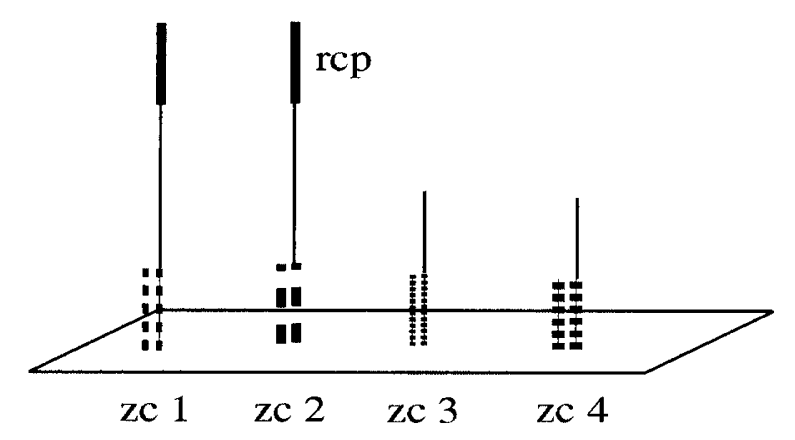

C:

a)

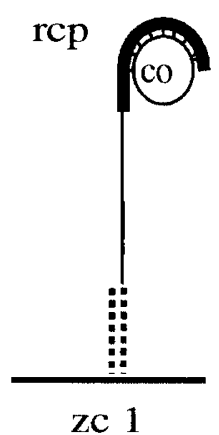

b)

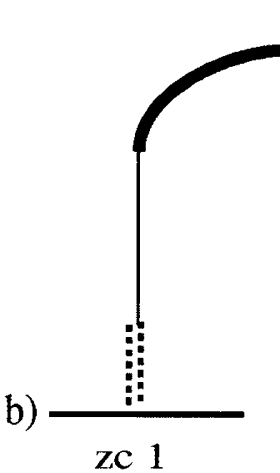

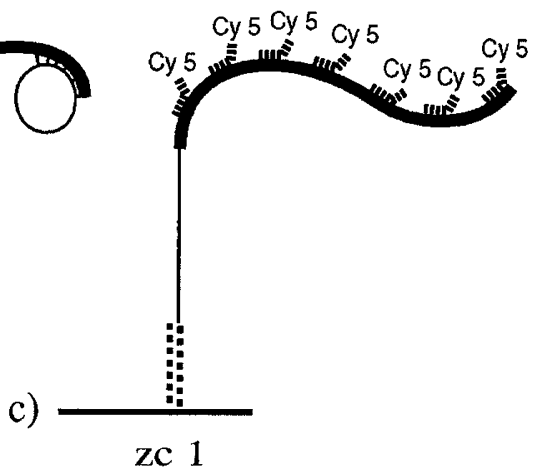

Figure 1.

A, Ligation detection reaction (LDR) in solution. (a) Upstream probe (up) with nucleotide on 3' end for KRAS codon 12 wild-type and specific zipcode 1 (zc 1) on 5 ' end anneals perfectly to template DNA. This allows ligation with downstream probe $(d p)$ attached to rolling circle primer ( $r c p)$. (b) A different upstream probe carrying correct 3' nucleotide for KRAS codon 12 mutation (GGC-GTC), anneals perfectly to mutated template DNA and ligates mutation specific zipcode 2 (zC 2) with rolling circle primer. Only in the presence of mutated template DNA will the corresponding upstream probe be ligated to the rolling circle amplification (RCA) primer. B, Hybridization of LDR product to generic zipcode microarray. Zipcodes of ligated and unligated probes are hybridized to their corresponding zipcode address of known location on the generic microarray. C, Rolling circle amplification. Only after successful ligation are zipcodes attached to the rolling circle primer (RCP), permitting RCA. (a) Circularized oligonucleotides anneal to RCPs. (b) Elongation of RCP in isothermal primer extension reaction. (c) Decoration with complementary fluorescently labeled oligonucleotides increasing fluorescent signal generated by each ligation event. 
tary strand on the slide. After LDR only zipcode addresses designated for the mutations present in the template PCR are attached to a rolling circle primer, permitting RCA. Circularized oligonucleotides are hybridized to the microarray slide, attaching to the rolling circle primers. In an isothermal primer extension reaction, the rolling circle primer is elongated on the circularized oligonucleotide in a multimeric fashion. The elongated RCA primer product is then decorated with complementary fluor-oligonucleotides, and the microarray slide is read by a scanner. Amplified signal will only occur at zipcode address locations corresponding with mutations present in the template DNA.

RCA amplification of the microarray-based PCR/ LDR increased signals so that LDR could now be performed using all 17 pairs of probes. In an experiment comparing the assay with and without RCA, sufficient signal for mutation detection was possible only when RCA was used (Fig. 2). Nine point mutations in KRAS exon 1, codons 12 and 13, and eight point mutations in TP53 exon 7 were used to validate the specificity of multiplex mutation detection with RCA enhancement. RCA-enhanced, microarray-based PCR/LDR displayed highly specific detection of all mutations ( $p<0.01$ in all cases). The average fluorescent signal generated by the correct mutation was 114 times greater than any background or nonspecific fluorescence (Tables 1, 2, and 3, Fig. 3). Thus, the improved signal-to-noise ratio obtained with RCA resulted in high discrimination of ligation signals, detecting one mutated allele in the presence of an excess of 90 to 120 wild-type alleles (Table 3).

\section{Discussion}

Because of signal enhancement with RCA, detection of KRAS and TP53 mutations is now possible from a multiplex LDR. All 17 point mutations were detected
A)

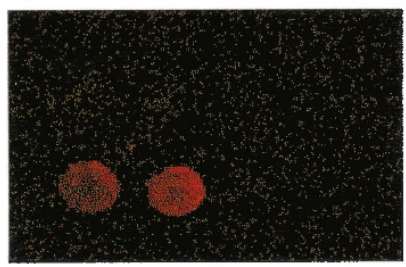

B)

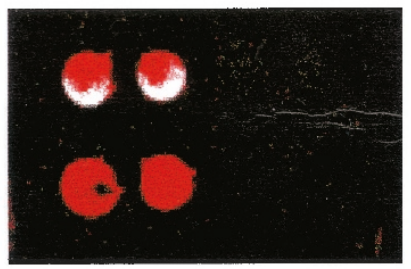

b

C)

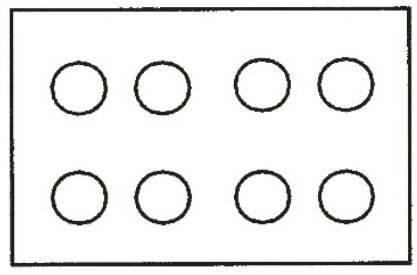

a

D)

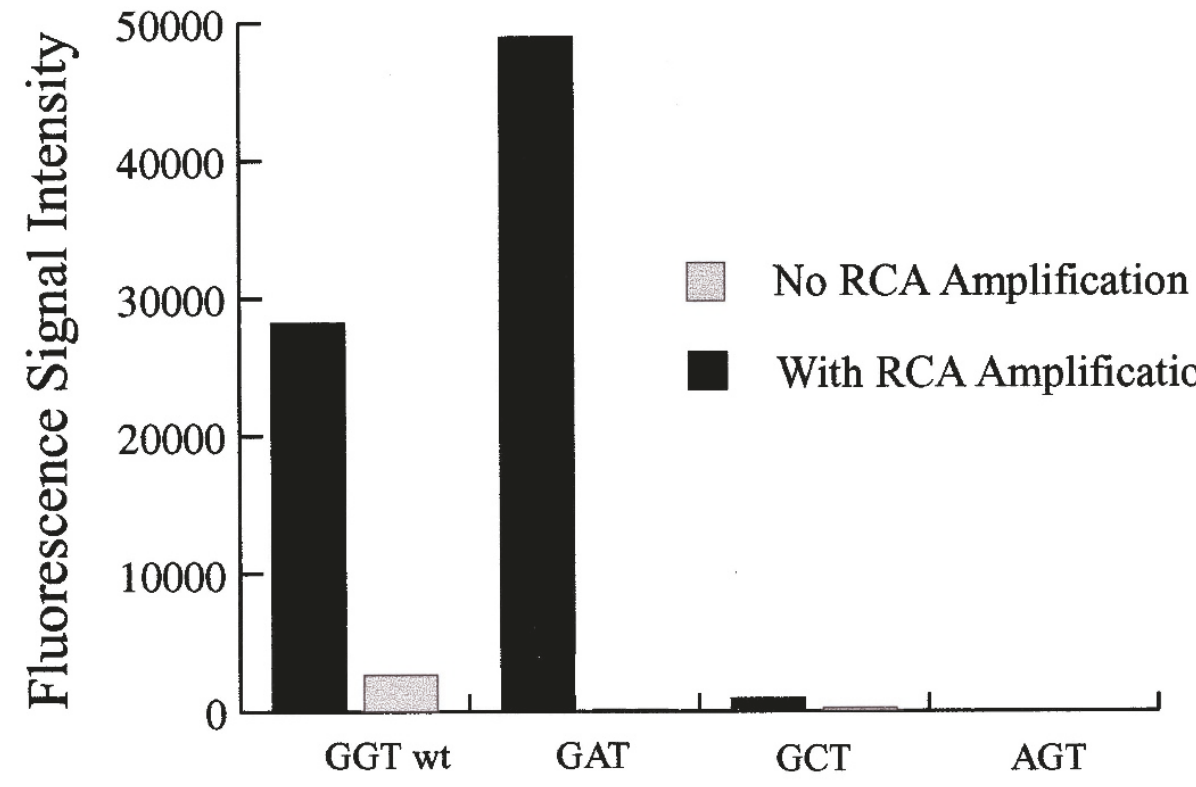

$K R A S$ exon 1 codon 12 mutations

Figure 2.

Comparison of signal intensities for LDR-microarray assays with and without RCA for KRAS exon 1 codon 12 (GGT wt and GAT). Multiplex ligation containing all 17 pairs of probes was performed with 1:1 mutation/wild-type PCR mixture. A, With RCA signal amplification, both GGT wt and GAT were correctly detected. B, Without RCA amplification, when a Cy-5 fluorophore is directly attached to the downstream probe, only wild-type DNA can be detected, whereas the GAT mutation remains undetectable. C, Outlay of handspotted zipcode location corresponding with the following mutations (a) GGT wt, (b) GAT, (c) GCT, and (d) AGT. D, Graph: comparison of signal intensities with and without RCA signal amplification under same scanning conditions. 
Table 1. Detection of TP53 Exon 7 Mutations in a Multiplex Reaction Containing All Probes by Microarray-Based PCR/LDR with RCA Signal Amplification ${ }^{a, b}$

\begin{tabular}{|c|c|c|c|c|c|c|c|c|}
\hline \multirow[b]{2}{*}{ ZIPCODES } & \multicolumn{8}{|c|}{ DNA: TP53 Exon 7} \\
\hline & 237:ATA & 244: GTC & 245: AGC & 245: GTC & 248:TGG & 248: $C A G$ & 248: CTG & 249: AGT \\
\hline Codon 237: ATA & $3069 \pm 347$ & $12 \pm 3$ & $4 \pm 7$ & $100 \pm 19$ & $100 \pm 41$ & $100 \pm 28.5$ & $223 \pm 43$ & $102 \pm 51$ \\
\hline Codon 244: GTC & $62 \pm 37$ & $9311 \pm 270$ & (2) \pm 4 & $40 \pm 20$ & $86 \pm 41$ & $222 \pm 35.9$ & $461 \pm 46$ & $185 \pm 82$ \\
\hline Codon 245: AGC & $80 \pm 20$ & $0 \pm 1$ & $1920 \pm 520$ & $49 \pm 17$ & $98 \pm 40$ & $118 \pm 29.8$ & $195 \pm 37$ & $157 \pm 29$ \\
\hline Codon 245: GTC & $42 \pm 61$ & $1 \pm 1$ & $1 \pm 3$ & $881 \pm 421$ & $0 \pm 13$ & $0 \pm 10.6$ & $85 \pm 17$ & $0 \pm 5$ \\
\hline Codon 248: TGG & $396 \pm 49$ & $10 \pm 4$ & $8 \pm 7$ & $31 \pm 20$ & $12,849 \pm 2289$ & $11 \pm 44.6$ & $171 \pm 16$ & $143 \pm 83$ \\
\hline Codon 248: CAG & $73 \pm 23$ & $1 \pm 2$ & $3 \pm 4$ & $38 \pm 14$ & $0 \pm 24$ & $3681 \pm 602$ & $109 \pm 16$ & $65 \pm 11$ \\
\hline Codon 248: CTG & $84 \pm 5$ & $4 \pm 3$ & $1 \pm 5$ & $27 \pm 16$ & $6 \pm 29$ & $71 \pm 16.3$ & $5569 \pm 2566$ & $118 \pm 62$ \\
\hline Codon 249: AGT & $2 \pm 1$ & $0 \pm 1$ & $3 \pm 6$ & $19 \pm 16$ & $219 \pm 849$ & $23 \pm 24.1$ & $135 \pm 22$ & $3189 \pm 1041$ \\
\hline $\begin{array}{l}{ }^{a} \text { Values are indica } \\
{ }^{b} \text { Each multiplex re } \\
\text { Upstream probes } \\
\text { (Codon 12: GGT): } \\
\text { (Codon 12: GAT): } \\
\text { (Codon 12: GCT): } \\
\text { (Codon 12: GTT): } \\
\text { (Codon 12: AGT): } \\
\text { (Codon 12: CGT): } \\
\text { (Codon 12: TGT): } \\
\text { (Codon 13: GGC w } \\
\text { (Codon 13: GAC): } \\
\text { (Codon 13: GCC): } \\
\text { (Codon 13: GTC): } \\
\text { Downstream probe } \\
\text { TGGCGTAGGCAAG } \\
\text { GACATCACAGCTGAG } \\
\text { Upstream probes } \\
\text { (Codon 237: ATA): } \\
\text { (Codon 244: GTC): } \\
\text { (Codon 245: AGC): } \\
\text { (Codon 245: GTC): } \\
\text { (Codon 248: TGG): } \\
\text { (Codon 248: CTG): } \\
\text { (Codon 248: CAG): } \\
\text { (Codon 249: AGT): } \\
\text { Downstream prob } \\
\text { TGTAACAGTTCCTG } \\
\text { CGGCATGAACCGG } \\
\text { GCATGAACCGGAG } \\
\text { CATGAACGGAGG } \\
\text { GGAGGCCCATCCTC } \\
\text { GAGGCCCATCCTCF } \\
\text { CCCATCCTCACCAT }\end{array}$ & $\begin{array}{l}\text { ted as fluorescer } \\
\text { eaction contained } \\
\text { KRAS exon 1: } \\
\text { GCTGAGGTCGAT } \\
\text { GCTGCGATCGAT } \\
\text { GCTGTACCCGAT } \\
\text { CGCAAGGTAGGT } \\
\text { CGCACGATAGGT } \\
\text { CGCACGATAGGT } \\
\text { GGTCAGGTTACC } \\
\text { Nt): GGTCAAGCT1 } \\
\text { GGTCCGATTACC } \\
\text { GGTCAAGCTTCG } \\
\text { CCGTCATCGCAC } \\
\text { es KRAS exon } 1 \\
\text { aAGTGCCTATCAC } \\
\text { aGATAGGACATGC } \\
\text { TP53 exon 7: } \\
\text { : TACCGGTCGGT } \\
\text { : CGCAGCTGGCT } \\
\text { : GGTCGCTGCGC } \\
\text { : AGGTGCTGCGC } \\
\text { : AGGTGGTCCGC } \\
\text { : GCTG CGCA GG } \\
\text { : AGGTCGCACGC } \\
\text { : CGCAGGTCGCT } \\
\text { es TP53: } \\
\text { GCATGGGCATCAC } \\
\text { aAGGCCCATCATC } \\
\text { iGCCCATCATCAC } \\
\text { :CCCATCCTCATC } \\
\text { CACCATCATCAC } \\
\text { ACCATCATCATCA } \\
\text { TCATCACAATCAC }\end{array}$ & $\begin{array}{l}\text { 1ce signal intensit } \\
\text { the following pr } \\
\text { GCTGAGGTCGCA } \\
\text { GGTCAGGTGCTG } \\
\text { GCTGTACCCGCA } \\
\text { GGTCTACCGCTG } \\
\text { GGTCTACCGCTG } \\
\text { GCTGCGATCGCA } \\
\text { TCGTGAGGACATC } \\
\text { GGTCCGATGCTG } \\
\text { TGAGGACATCAA } \\
\text { CAAGACGACTTTT } \\
\text { AGCTGAGGATAG } \\
\text { GA; } \\
\text { CCGATCGATGCTC } \\
\text { GAGGTAGGTCGA } \\
\text { AAGGTTACCCGA } \\
\text { AAGGTTACCCGC } \\
\text { ACGATTACCGCT } \\
\text { GTCTACCCGATAG } \\
\text { GATACCTACCGGT } \\
\text { GCGATAGGTTAC } \\
\text { CAGCTGAGGATAC } \\
\text { ACAGCTGAGGAT } \\
\text { AGCTGAGGATAG } \\
\text { ACAGCTGAGGAT } \\
\text { AGCTGAGGATAG } \\
\text { ACAGCTGAGGATA } \\
\text { AGCTGAGGATAG }\end{array}$ & $\begin{array}{l}\text { ty } \pm \text { standard de } \\
\text { obes }\left(5^{\prime}-3^{\prime}\right) \text { : } \\
\text { AAACTTGTGGTA } \\
\text { AAACTTGTGGTA } \\
\text { AAACTTGTGGTA } \\
\text { AAACTTGTGGTA } \\
\text { ATATAAACTTGTC } \\
\text { ATATAAACTTGTC } \\
\text { ATATAAACTTGTG } \\
\text { 'AATGTGGTAGTT } \\
\text { TGTGGTAGTTGG } \\
\text { TGTGGTAGTTGG } \\
\text { TGTGGTAGTTGGA } \\
\text { GACATGCGA, GT } \\
\text { GACCACCATCCAC } \\
\text { TATGTGTAACAG } \\
\text { TAACAGTTCCTGC } \\
\text { AACAGTTCCTGC } \\
\text { GGCATGGGCGGC } \\
\text { GTCATGGGCGGC } \\
\text { CCATGGGCGGCA } \\
\text { CGCGGCATGAAC } \\
\text { GGACATGCGA, } \\
\text { AGGACATGCGA, } \\
\text { GACATGCGA, } \\
\text { AGGACATGCGA, } \\
\text { GACATGCGA, } \\
\text { AGGACATGCGA, } \\
\text { GACATGCGA; }\end{array}$ & $\begin{array}{l}\text { viation (SD) for } \\
\text { GTTGGAGCTGG, } \\
\text { GTTGGAGCTGA, } \\
\text { GTTGGAGCTGC, } \\
\text { GTTGGAGCTGT, } \\
\text { aGTAGTTGGAGC } \\
\text { aGTAGTTGGAGC } \\
\text { aGTAGTTGGAGC } \\
\text { GGAGCTGGGGC } \\
\text { AGCTGGGGA, } \\
\text { AGCTGGTGC, } \\
\text { AGCTGGTGT, } \\
\text { TGGCGTAGGCAA } \\
\text { CTACAACTACATf } \\
\text { TTCCTGCATGGT } \\
\text { CATGGGCA, } \\
\text { ATGGGCGT, } \\
\text { CATGAACT, } \\
\text { ATGAACCT, } \\
\text { TGAACCA, } \\
\text { CGGAGT, }\end{array}$ & $\begin{array}{l} \\
\text { TA, } \\
\text { TC, } \\
\text { TT, } \\
\text { GAGTGCCATCACAGC }\end{array}$ & $\mathrm{n}$, which is define & for a specific m & AAGAGTGCCTT- \\
\hline
\end{tabular}

with high specificity and hybridization signals generated by the correct mutation exceeded background fluorescence and nonspecific binding by an average of 14-fold, allowing discrimination of mutated alleles despite a 100-fold or greater excess of wild-type alleles. In our hands these results could not be achieved using previously described methods, which do not use signal enhancement. Future studies will address the question whether discrimination can be further increased by ligation at higher temperature.

Many of the reagents used in this assay are generic; that is, they are the same for all experiments. Thus, one may use the same universal microarray and the same circular oligonucleotides for a variety of assays. Adaptation of the method to the detection of any new target of interest requires only the synthesis of the two specific probe-oligonucleotides for each mutation, deletion, or insertion of interest.
The combination of a solid substrate with an isothermal reaction, performed at $37^{\circ} \mathrm{C}$, permits automation of the method without complex instrumentation requirements. The system is now ready for automation and the Biomek (Beckman Coulter, Fullerton, California) platform has been programmed for large-scale analysis, lessening reaction time and volumes and providing cost and time savings while increasing reproducibility between reactions. We anticipate the extension of this platform to the analysis of low abundance mutations in oncogenes and tumor suppressor genes in clinical samples and its potential use for cancer risk assessment.

Although successful ligation is clearly above background signals in our set of experiments, positive signal intensities vary. Most of the variation within our set of experiments can be attributed to differences in the printing of the microarray slides. Furthermore, as 


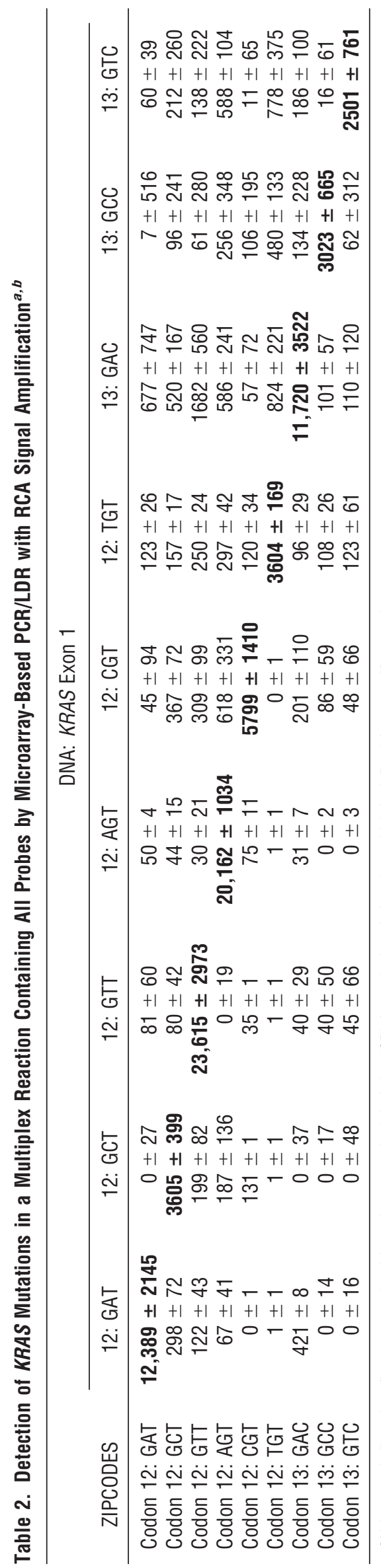

reported by others (Day et al, 1995; Khanna et al, 1999), this introduces further variations depending on the probes used. Nevertheless, our results indicate that, under proper conditions, mutant alleles can be detected when present in concentrations as low as $1 \%$ of the mixture. We wish to emphasize that the present assay does not provide a precise quantitation of the relative amount of different mutant alleles in a mixture. Precise quantitation for future clinical applications will require development of calibration standards, which can be used to normalize the different ligation efficiencies.

\section{Material and Methods}

\section{Microarray Printing}

Synthesis of 3' amine-modified, 24-base oligonucleotide zipcodes was performed on an ABI DNA synthesizer (Applied Biosystems, Foster City, California). The zipcodes were purified by gel electrophoresis and diluted to $40 \mu \mathrm{M}$. Zipcodes were robotically spotted by an Omnigrid Microarrayer (GeneMachines, San Carlos, California) onto 3D-Link slides (SurModics, Eden Prairie, Minnesota) with at least five replicates of each zipcode. Oligonucleotides were allowed to bind to the slides overnight at room temperature in $75 \%$ humidity. The slides were subsequently blocked in $50 \mathrm{~mm}$ ethanolamine, $0.1 \mathrm{M}$ Tris $(\mathrm{pH}$ 9), and $0.1 \%$ SDS for 1 hour, and then washed for one hour in $\times 4$ SSC and $0.1 \%$ SDS at room temperature. The slides were spun dry in a centrifuge and stored desiccated in a lightproof box until use.

\section{Oligonucleotide Probe Synthesis and Purification}

Upstream and downstream probes were synthesized on an ABI DNA synthesizer. Circularized oligonucleotide for RCA is as follows: 5' GTCAGAACTGTGAAGATCGCTATAATCGCATGTCCTATCCTCAGCTGTGATCATACTGACGACGAGTCAAACTGTGAAGATCGCTTATAAAACTGTGAAGATCGCTTATAAGACTCGTC-3'.

\section{DNA Extraction from Cell Lines}

Cell lines of known KRAS (Codon 12: LS 180: GGTGAT, SW 1116:GGT-GCT, SW 620:GGT-GTT, A 549: GGT-AGT; Codon 13: DLD-1: GGC-GAC) and TP53 genotype (Codon 241: DLD-1: TCC-TTC, Codon 248: OVCAR-3: CGG-CAG, SKOV-3: CGG-CTG) were grown under standard conditions to confluence. Cells were then spun into a pellet, and DNA was extracted with a QIAamp DNA Mini Kit (Qiagen, Chatsworth, California) according to protocol. Following extraction, DNA was quantified by PicoGreen (Molecular Probes, Eugene, Oregon) on a CytoFluor Multi-Well Plate Reader, Series 4000 (PerSeptive Biosystems, Framingham, Massachusetts), and stored in doubledistilled $\mathrm{H}_{2} \mathrm{O}$ at $4^{\circ} \mathrm{C}$ until use. Except for the cell lines SW620 and A549, which were monoclonal, mutated samples contained $50 \%$ mutated and $50 \%$ wild-type DNA. 
Table 3. Detection of Mutated Alleles in a Pool of Wild-Type Alleles in a Multiplex Reaction ${ }^{a, b}$

\begin{tabular}{|c|c|c|c|c|}
\hline \multirow[b]{2}{*}{ ZIPCODES } & \multirow{2}{*}{$\frac{\text { KRAS Exon } 1}{12: \text { GAT }}$} & \multicolumn{3}{|c|}{ TP53 Exon 7} \\
\hline & & ZIPCODES & 248: TGG & 248: $C A G$ \\
\hline Wt: Mutation & $1: 120$ & Wt: mutation & $1: 90$ & $1: 90$ \\
\hline Codon 12: GAT & $129 \pm 78$ & codon 237: ATA & $358 \pm 74$ & $271 \pm 89$ \\
\hline Codon 12: GCT & $24 \pm 11$ & codon 244: GTC & $129 \pm 25$ & $347 \pm 37$ \\
\hline Codon 12: GTT & $112 \pm 51$ & codon 245: AGC & $165 \pm 47$ & $195 \pm 44$ \\
\hline Codon 12: AGT & $890 \pm 504$ & codon 245: GTC & $2 \pm 2$ & $0 \pm 1$ \\
\hline Codon 12: CGT & $6 \pm 5$ & codon 248: TGG & $3928 \pm 1028$ & $245 \pm 112$ \\
\hline Codon 12: TGT & $1 \pm 1$ & codon 248: CAG & $114 \pm 70$ & $685 \pm 460$ \\
\hline Codon 13: GAC & $16 \pm 9$ & codon 248: CTG & $33 \pm 20$ & $31 \pm 24$ \\
\hline Codon 13: GCC & $19 \pm 12$ & codon 249: AGT & $13 \pm 53$ & $0 \pm 1$ \\
\hline Codon 13: GTC & $0 \pm 7$ & & & \\
\hline
\end{tabular}

${ }^{a}$ Values are indicated as fluorescence signal intensity \pm standard deviation (SD) for each zipcode location, which is defined for a specific mutation.

${ }^{b}$ Each multiplex reaction contained the following probes $\left(5^{\prime}-3^{\prime}\right)$ : (see Table $\left.1 \mathrm{~A}\right)$.

\section{DNA Extraction from Paraffin Sections}

DNA extracted from paraffin-embedded archival tumors was kindly provided Dr. G. Capella (Institut Catala d' Oncologia, L'Hospitalet, Barcelona, Spain). The tumors harbored known mutations in p53 exon 7 (Codon 244: GGC-GCT, Codon 245: GGC-AGC, GGC-GTC, GGC-GAC, Codon 248: CGG-TGG, Codon 249: AGG-AGT). Ten-micrometer sections were cut from paraffin blocks, and morphologically distinct regions were microdissected. DNA was extracted using a QIAamp DNA Mini Kit.

\section{Synthesis of Mutated DNA}

For five mutations not available as cell lines or tumor samples, synthetic primers containing these mutations were synthesized. Primer extension reactions were performed with Amplitaq Gold (Applied Biosystems, Foster City, California) on wild-type KRAS exon 1 or P53 exon 7 amplicons (Table 3). Because only a single base mismatch existed at the mutated site between the wild-type template and the primer, the primer was able to anneal to the template. Primer extension reactions were conducted under standard PCR conditions ( 40 cycles at $94^{\circ} \mathrm{C}$ for 30 seconds, $55^{\circ} \mathrm{C}$ for 45 seconds, $72^{\circ} \mathrm{C}$ for 45 seconds after initial denaturation for 12 minutes at $94^{\circ} \mathrm{C}$, and a final extension for 10 minutes at $72^{\circ} \mathrm{C}$ ). Reaction products contained the mutated primer sequence, whereas the rest of the strand was wild type.

\section{PCR Conditions}

Exons of interest were amplified from cell lines and tumor DNA samples by PCR. Amplification was performed in $30 \mu \mathrm{l} \times 1$ Taq buffer (PerkinElmer, Norwalk, Connecticut), $2 \mathrm{~mm} \mathrm{MgCl} 2,250 \mu \mathrm{M}$ dNTP, $0.5 \mu \mathrm{M}$ forward and reverse primers, $0.8 \mathrm{U}$ Amplitaq Gold (Applied Biosystems), and $30 \mathrm{ng}$ of genomic DNA. The following sets of primers were used: KRAS exon 1, forward: 5'-GGCTGAATATAAACTTGTGG-3', reverse: 5'-AATGGTCCTGCACCAGTAAT-3'; TP53 exon 7, for- ward: 5'-CCACAGGTCTCCCCAAGG-3', reverse: 5'TGGCAAGTGGCTCCTGAC-3'. Amplification was achieved by 35 or 40 cycles at $94^{\circ} \mathrm{C}$ for 30 seconds, $55^{\circ} \mathrm{C}$ for 45 seconds, $72^{\circ} \mathrm{C}$ for 45 seconds after initial denaturation for 12 minutes at $94^{\circ} \mathrm{C}$, and a final extension of 10 minutes at $72^{\circ} \mathrm{C}$. One microliter of the PCR product was analyzed on an ethidium bromide (EtBr)-stained, 3\% agarose gel to verify amplification product and for quantitation. PCR products were stored at $-20^{\circ} \mathrm{C}$.

\section{LDR Reaction}

Mutations were detected using sequence-specific ligation of oligonucleotide probes (Tables 1, 2, and 3). Upstream probes were designed to carry the point mutation on their $3^{\prime}$ end and are attached to a zipcode address on their $5^{\prime}$ end. Every upstream probe specific for one mutation carries a different zipcode address designated for this mutation. Downstream probes carry a rolling circle primer on their 3 ' end. Only in the presence of mutated template DNA will the corresponding upstream probe be ligated to the downstream probe and, hence, combine the designated zipcode address with the RCA primer (Fig. 1).

Multiplex LDR was conducted in a 40- $\mu$ I mixture (20 $\mathrm{mm}$ Tris- $\mathrm{HCl}, \mathrm{pH} 8.3 ; 2.5 \mathrm{~mm} \mathrm{KCl} ; 10 \mathrm{~mm} \mathrm{MgCl} ; 0.5$ mм NAD $; 0.01 \%$ Triton X-100) containing 200 nм of each upstream probe and $25 \mathrm{~nm}$ of each downstream probe. The reaction mixture was heated for 5 minutes at $94^{\circ} \mathrm{C}$ and then chilled on ice. After the reaction mixture had cooled, $8 \cup$ Ampligase (Epicentre, Madison, Wisconsin) was added, and the reaction was run for 20 cycles $\left(94^{\circ} \mathrm{C}\right.$ for 30 seconds and 4 minutes at either 65 or $69^{\circ} \mathrm{C}$ ) in a thermocycler (Perkin-Elmer 9700). The reactions were then placed on ice and $1 \mathrm{ul}$ of $0.5 \mu \mathrm{M}$ EDTA was added to each tube to halt the reaction.

\section{Microarray Hybridization}

LDR products were then hybridized to a generic microarray, carrying zipcode addresses. Ligation 


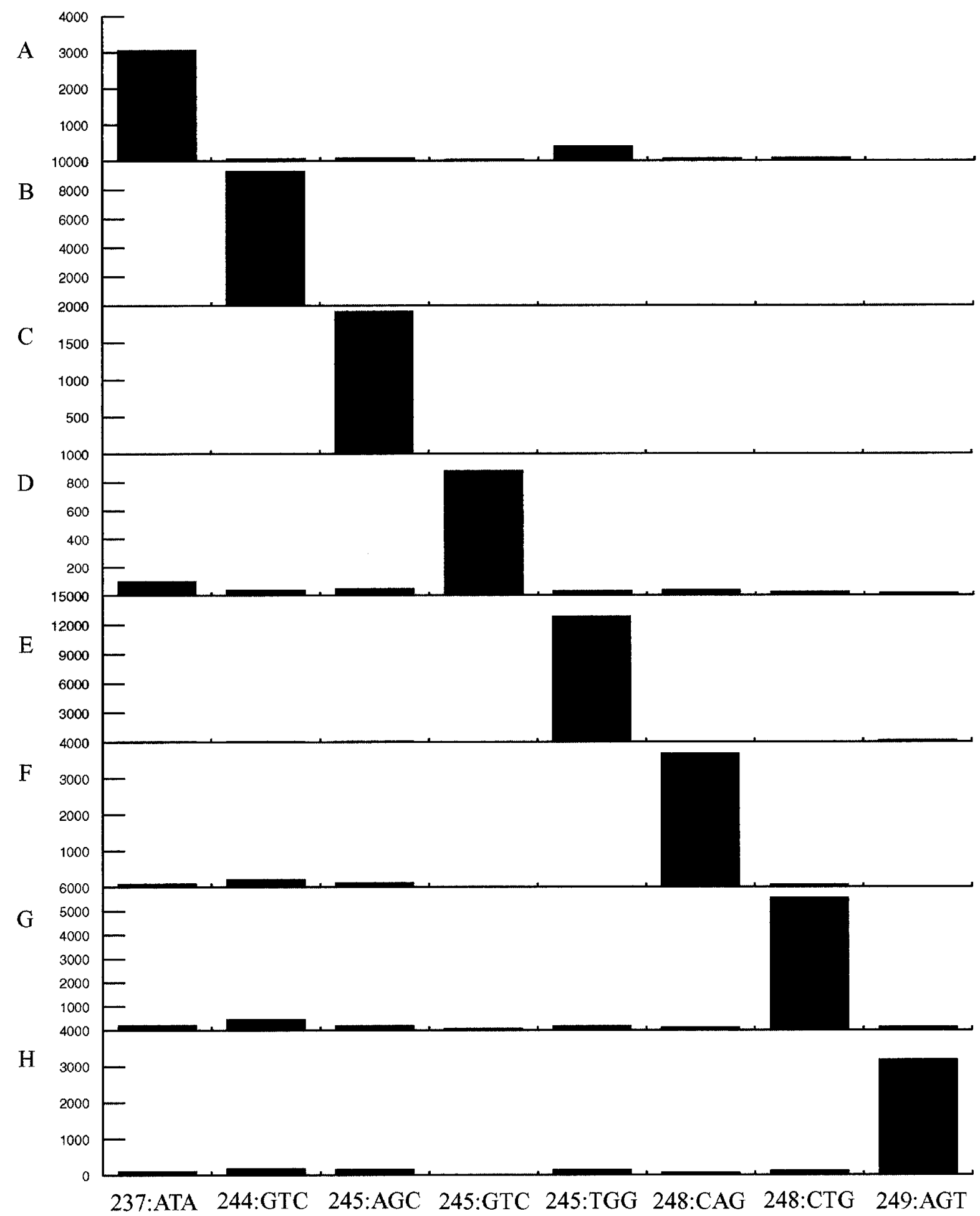

Figure 3.

Detection of TP53 exon 7 mutations in a multiplex reaction, each containing all probes by microarray-based PCR/LDR with RCA signal amplification (Table 1). X axis: Every geographically distinct zipcode location on the microarray is defined for a specific mutation. $Y$ axis: Fluorescent signal intensity; experiments for detection of eight hotspot mutations in TP53 exon 7 are stacked: Codon 237:ATA, Codon 244: GTC, Codon 245: AGC, Codon 245: GTC, Codon 245: TGG, Codon 248: CAG, Codon 248: CTG, Codon 249: AGT.

product $(9.5 \mu \mathrm{l})$ was added to $22.8 \mu \mathrm{l}$ of hybridization solution $(20 \%$ formamide, $\times 4$ Denhardt's solution, $0.8 \%$ SDS, $\times 6$ SSPE) and $1.8 \mu$ l blocking solution (7.2 $\mu \mathrm{g}$ polyA, $14.4 \mu \mathrm{g}$ tRNA, and $36 \mu \mathrm{g}$ human Cot-DNA) at $65^{\circ} \mathrm{C}$. The solution was centrifuged at $16,000 \times g$ for 5 minutes; the supernatant (approximately $30 \mu \mathrm{l}$ ) was applied to the microarray face and topped with a glass coverslip. Hybridization occurred for 1 hour at $65^{\circ} \mathrm{C}$ in a humidified HybChamber (GeneMachines). Following hybridization, the slides were washed at 
room temperature in $\times 1$ SSC and $0.3 \%$ SDS for 10 minutes on a rotating table. Slides were then washed twice at room temperature in $\times 0.2$ SSC for 20 minutes, spun dry in a centrifuge, and stored in a lightproof box.

\section{Rolling Circle Amplification}

RCA was used to elongate the rolling circle primer contained in the hybridized LDR product. The array was circumscribed with a hydrophobic Pap Pen (Electron Microscopy Sciences, Fort Washington, Pennsylvania), and the slides were equilibrated in $\times 1$ potassium glutamate buffer (KGB) (Hanish and McClelland, 1988) for 5 minutes on a rotating table at room temperature. Following equilibration, slides were briefly shaken dry, and prehybridization solution ( $\times 0.75 \mathrm{KGB}$ buffer, 0.1\% Tween, $200 \mu \mathrm{g} / \mu \mathrm{l}$ BSA, and $50 \mathrm{~nm}$ circularized oligonucleotide) was applied to the array face. The slides were incubated in a hybridization chamber for 1 hour at $42^{\circ} \mathrm{C}$, after which the slides were shaken dry. Slides were then placed on aluminum blocks at $4^{\circ} \mathrm{C}$, and $40 \mu \mathrm{l}$ of amplification solution ( $\times 0.75 \mathrm{KGB}$ buffer, $6.7 \mathrm{~mm}$ DTT, 0.1\% Tween, $0.2 \mathrm{~mm}$ dNTP, $200 \mu \mathrm{g} / \mu \mathrm{l}$ BSA, $25 \mathrm{~nm}$ circularized oligonucleotide, $1.5 \mathrm{~mm}$ single-stranded binding protein [Promega, Madison, Wisconsin], and $0.45 \mathrm{U} / \mu$ I Sequenase [United States Biochemical, Cleveland, Ohio]) was placed on each array. Slides were placed in hybridization chambers and incubated at $37^{\circ} \mathrm{C}$ for 30 minutes. After amplification, the slides were washed in $\times 2$ SSC, $0.02 \%$ BSA, and $0.1 \%$ Tween for 5 minutes at room temperature. RCA product was visualized through addition of a decorator solution ( $\times 6$ SSC, $0.1 \%$ Tween, $500 \mu \mathrm{g} / \mathrm{ml}$ herring sperm DNA, and $30 \mathrm{~nm}$ fluorescent 18 base oligonucleotide) and hybridization for 30 minutes at $37^{\circ} \mathrm{C}$. Unbound decorator was removed with two 5 -minute washes at $37^{\circ} \mathrm{C}(\times 2$ SSC, $0.02 \%$ BSA, $0.1 \%$ Tween), followed by a final 5 -minute wash at room temperature $(\times 2$ SSC, $0.02 \%$ $\mathrm{BSA}$ ), and then spun dry in a centrifuge and stored in a lightproof box. Decorator: Cy 5 - ACTGTGAAGATCGCTTAT-DNP.

\section{Scan}

Slides were then scanned at $635 \mathrm{~nm}$ on a Genepix 4000A Scanner (Axon Instruments, Foster City, California) and analyzed with GenePix Pro 3.0 Software (Axon Instruments).

\section{References}

Broude N, Sano T, Smith CL, and Cantor CR (1994). Enhanced DNA sequencing by hybridization. Proc Natl Acad Sci USA 91:3072-3076.
Day DJ, Speiser PW, White PC, and Barany F (1995). Detection of steroid 21-hydroxylase alleles using genespecific PCR and a multiplexed ligation detection reaction. Genomics 2:152-162.

Eggerding F, lovannisci DM, Brinson E, Grossman P, and Winn-Deen ES (1995). Fluorescence-based oligonucleotide ligation assay for analysis of cystic fibrosis transmembrane conductance regulator gene mutations. Hum Mutat 5:153165.

Gerry NP, Witowski NE, Day J, Hammer RP, Barany G, and Barany $F$ (1999). Universal DNA microarray method for multiplex detection of low abundance point mutations. J Mol Biol 292:251-262.

Hacia JG, Brody LC, Chee MS, Fodor SP, and Collins FS (1996). Detection of heterozygous mutations in BRCA1 using high-density oligonucleotide arrays and two-colour fluorescence analysis. Nat Genet 14:441-447.

Hanish $\mathrm{J}$ and McClelland M (1988). Activity of DNA modification and restriction enzymes in KGB, a potassium glutamate buffer. Gene Anal Tech 5:105-107.

Hatch A, Sano T, Misasi J, and Smith CL (1999). Rolling circle amplification of DNA immobilized on solid surfaces and its application to multiplex mutation detection. Genet Anal 15: 25-40.

Khanna M, Cao W, Zirvi M, Paty P, and Barany F (1999). Ligase detection reaction for identification of low abundance mutations. Clin Biochem 32:287-290.

Lizardi PM, Huang X, Zhu Z, Bray-Ward P, Thomas DC, and Ward DC (1998). Mutational detection and single-molecule counting using rolling-circle amplification. Nat Genet 19:225232.

Orita $\mathrm{M}$, Iwahana $\mathrm{H}$, Kanazawa $\mathrm{H}$, Hayashi $\mathrm{K}$, and Sekiya $\mathrm{T}$ (1989). Detection of polymorphisms of human DNA by gel electrophoresis as single-strand conformation polymorphisms. Proc Natl Acad Sci USA 86:2766-2770.

Pastinen T, Raitio M, Lindroos K, Tainola P, Peltonen L, and Syvanen AC (2000). A system for specific, high-throughput genotyping by allele-specific primer extension on microarrays. Genome Res 10:10331-10342.

Prezant T and Fishel-Ghodsian N (1992). Trappedoligonucleotide incorporation (TONI) assay, a simple method for screening point mutations. Hum Mutat 1:159-164.

Shuber AP, Michalowsky LA, Nass GS, Skoletsky J, Hire LM, Kotsopoulos SK, Phipps MF, Barberio DM, and Klinger KW (1997). High throughput parallel analysis of hundreds of patient samples for more than 100 mutations in multiple disease genes. Hum Mol Genet 6:337-343.

Thomas DC, Nardone GA, and Randall SK (1999). Amplification of padlock probes for DNA diagnostics by cascade rolling circle amplification or the polymerase chain reaction. Arch Pathol Lab Med 123:1170-1176.

Witowski NE, Leiendecker-Foster C, Gerry NP, McGlennen $\mathrm{RC}$, and Barany $\mathrm{G}$ (2000). Microarray-based detection of select cardiovascular disease markers. Biotechniques 29: 936-944. 